\title{
The Primates 2021 Most-Cited Paper Award
}

\author{
Masayuki Nakamichi ${ }^{1}$
}

Published online: 15 October 2021

(C) Japan Monkey Centre 2021

The two papers listed below were jointly the most frequently cited in 2020 among those published in Primates during the period from 2018 to 2019. Their authors thus contributed greatly to enhancing the reputation of our journal. For this achievement, each author will receive declarations attesting to their contributions.

Daniel P. Schofield, William C. McGrew, Akiko Takahashi, Satoshi Hirata: Cumulative culture in nonhumans: overlooked findings from Japanese monkeys? (Schofield et al. 2018).

Arijit Pal, Honnavalli N. Kumara, Partha Sarathi Mishra, Avadhoot D. Velankar, Mewa Singh: Extractive foraging and tool-aided behaviors in the wild Nicobar long-tailed macaque (Macaca fascicularis umbrosus) (Pal et al. 2018).
September 2021

Masayuki Nakamichi: Editor-in-Chief, Primates

Gen'ichi Idani:

General Director, Japan Monkey Centre

Naofumi Nakagawa:

Toshiro Mikami:
President, Primate Society of Japan Executive Editor, Springer, a part of Springer Nature
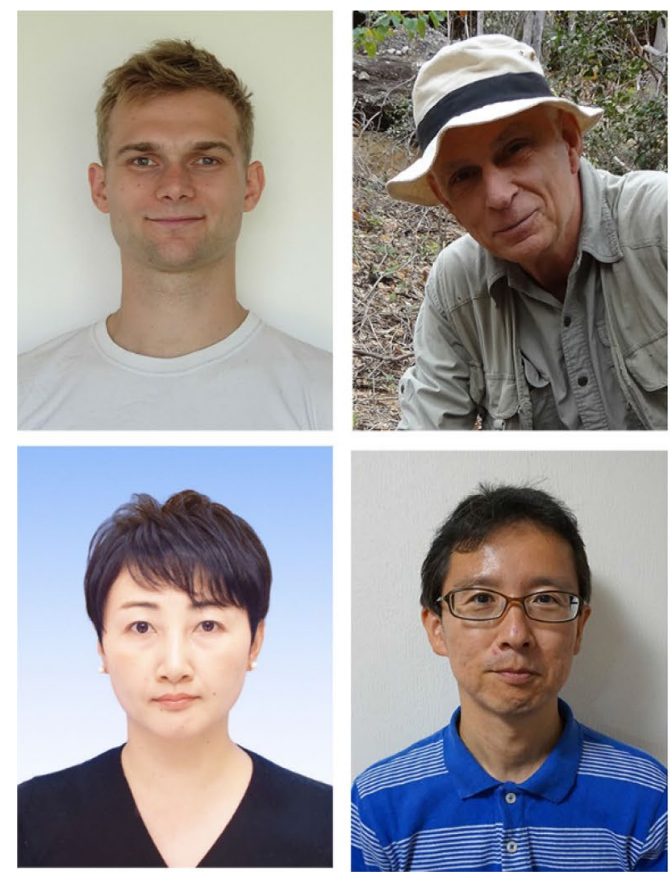

Daniel P. Schofield, William C. McGrew, Akiko Takahashi, Satoshi Hirata

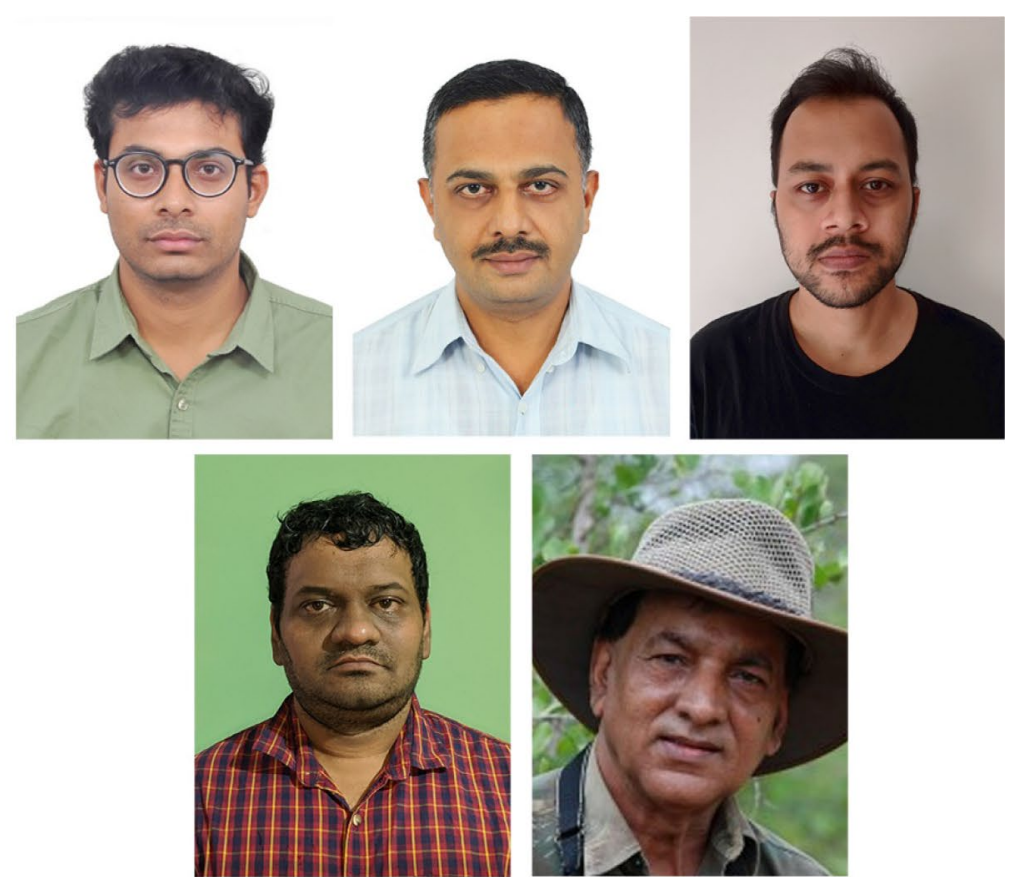

Arijit Pal, Honnavalli N. Kumara, Partha Sarathi Mishra, Avadhoot D. Velankar, Mewa Singh

Masayuki Nakamichi

naka@hus.osaka-u.ac.jp

1 Osaka University, Suita, Japan 


\section{References}

Pal A, Kumara HN, Mishra PS, Velankar AD, Singh M (2018) Extractive foraging and tool-aided behaviors in the wild Nicobar long-tailed macaque (Macaca fascicularis umbrosus). Primates 59:173-183. https://doi.org/10.1007/s10329-017-0635-6

Schofield DP, McGrew WC, Takahashi A, Hirata S (2018) Cumulative culture in nonhumans: overlooked findings from
Japanese monkeys? Primates 59:113-122. https://doi.org/10.1007/ s10329-017-0642-7

Publisher's Note Springer Nature remains neutral with regard to jurisdictional claims in published maps and institutional affiliations. 